\title{
Physical exercise in pancytopenia, what is the evidence
}

Keywords: physical exercise, pancytopenia, HSCT, physical therapy, thrombocytopenia

\section{Commentary}

The most effective treatment for hematologic malignancies involves high-dose chemotherapy (myeloablative chemotherapy) and, if necessary, the total body irradiation followed by hematopoietic stem cell transplantation (HSCT). The use of HSCT increases as the treatment technology improves, which resulted in reduced morbidity and increased life expectancy. ${ }^{1}$

The most relevant and frequently reported problems for patients with hematological malignancies are: decreased range of motion, reduced muscle strength, limited functional mobility and physical deconditioning and pain. In the lats years, the promising role of physical exercise programs as non-pharmacological adjuvant therapy for cancer patients is evident. These patients can benefit in terms of better levels of fitness, physical activity and quality of life, while fighting treatment-related symptoms. ${ }^{2,3}$

Therefore, physical exercise can be implemented before, during and after cancer treatment, despite the need for more robust evidence to support the exercise programs in relation to the most appropriate modality and intensity. ${ }^{3-6}$

Currently, there are countless systematic reviews presented in addition to clinical experience, where it is observed that interventions with exercise were well tolerated and safe for patients undergoing HSCT. It seems that starting the exercise intervention before or shortly after the transplant is beneficial, because a positive trend is shown. Thus, physical exercise in aerobic or resistance training is feasible, safe and beneficial in patients undergoing HSCT. ${ }^{7}$

Part of the physical-functional maintenance and rehabilitation process is the recognition of baseline characteristics prior to HSCT and monitoring throughout the process. The alignment of prescription, objectives and results must be constantly rethought, according to changes expected in this period, since the physical-functional capacity and the patient's needs fluctuate during treatment. For this reason, daily assessment is essential to recognize symptoms and readapt the exercise protocol. Laboratory tests are essential for monitoring HSCT. Physiotherapeutic conduct is linked to the variations observed in several exams, the blood count being a great ally in decision making. Within the blood count, we can highlight the hemoglobin and platelet values, traditionally recognized as limiting the realization of the rehabilitation protocol. Pancytopenia is an integral part of the post-HSCT scenario where we observe a decline in blood cell counts followed by a gradual increase. This variation directly influences the intensity of the proposed exercise, and should be checked frequently.,

Exercising during the period of severe cytopenia is still a matter of discussion between physical rehabilitation centers and reports in the literature. Researchers such asRexer et al consider thrombocytopenia (platelets $<10,000 \mu \mathrm{l}$ ) as a possible barrier to adherence to an exercise program. 8 In the study by Baummann, patients with platelet

\author{
Volume 5 Issue 4 - 2020
}

\author{
Suelen da Silva de Vargas,' Carine Lumi ${ }^{2}$ \\ 'Physiotherapist, Medical Sciences, University Federal do Rio \\ Grande do Sul, Brazil \\ ${ }^{2}$ Physiotherapist, Health Sciences, Universidade Federal de \\ Ciências da Saúde de Porto Alegre, Brazil
}

Correspondence: Suélen da Silva de Vargas, Physiotherapist, Rua Monsenhor Antônio Guilherme Grings, 51/1306, Porto Alegre, Rio Grande do Sul, Brazil, Tel +5551981769/3I, Emailsuelnv@terra.com.br

Received: July 08, 2020 | Published: August II, 2020

counts $\leq 10,000 \mu \mathrm{l}$ were excluded from the study.10 Articles already published, exercise therapy was interrupted or not performed, if the patient had platelet counts between $10-20,000 \mu 1$, and hemoglobin count $<8 \mathrm{~g} / \mathrm{dL}$. ${ }^{11-14}$

The problem is that patients in the post-HSCT phase routinely present critical values in laboratory tests. Therefore, following the exercise interruption guidance in this phase is synonymous with impaired functional performance and physical conditioning, promoting negative results and delaying the recovery process of these patients.

Apparently, exercises in cytopenic patients with adequate assessment and individualized prescription can be planned and performed according to the severity of the condition. In the clinical experience of the authors, regarding the performance of exercises with patients with severe cytopenia, we did not identify any harm to patients or undesirable events. Our clinical results are similar to those of Elter el al, in which no adverse events occurred during the execution of the exercise program with counts equal to $10,000 / \mu 1$, as also reported in other studies in similar contexts, supporting program security and improving physical performance. ${ }^{3,15} \mathrm{We}$ also found that with platelet counts $\leq 10,000 \mu 1$ and hemoglobin $<7$, after transfusion of blood products, we can measure the intensity of the proposed exercises without excluding them.

It is worth mentioning that these conducts must be essentially aligned between the multidisciplinary team and the patient, with the main objective of providing the beneficial effect of physical therapy and, mainly, avoiding complications resulting from cytopenia.

\section{Acknowledgments}

None.

\section{Conflicts of interest}

The author declares no conflict of interest. 


\section{References}

1. Copelan EA. Hematopoietic stem-cell mtransplantation. $N$ Engl J Med 2006;354:1813-1826.

2. Cipolat S, Pereira BB, Fereira FV. A influência da fisioterapia nos parâmetros respiratórios e na dispneia em crianças e adolescentes com leucemia. IN: $3^{\circ}$ Jornada Interdisciplinar em Saúde. Santa Maria, RS. 2011.

3. Wiskemann J, Huber G. Physical exercise as adjuvant therapy for patients undergoing hematopoietic stem cell transplantation. Bone Marrow Transplant. $2008 ; 41: 321-329$.

4. Liu RD, Chinapaw MJ, Huijgens PC, et al. Physical exercise interventions in haematological cancer patients, feasible to conduct but effectiveness to be established: a systematic literature review. Cancer Treat Rev. 2009;35(2):185-192.

5. Knols R, Aaronson NK, Uebelhart D, et al. Physical exercise in cancer patients during and after medical treatment: a systematic review of randomized and controlled clinical trials. J Clin Oncol. 2005;23(16):38303842 .

6. Velthuis MJ, Agasi - Ldenburg SC, Aufdemkampe G, et al. The effect of physical exercise on cancer-related fatigue during cancer treatment: a meta-analysis of randomised controlled trials. Clin Oncol (RColl Radiol). 2010;22:208-221.

7. Inge EPM, Hans T, Potting CA, et al. Physical exercise for patients undergoing hematopoietic stem cell transplantation: systematic review and meta-analyses of randomized controlled trials. Physical Therapy. 2013;93(4):514-528.
8. Rexer P, Kanphade G, Murphy S. Feasbility of an exercise program for patients with thrombocytopenia undergoing hematopoietic stem cell transplant. J Acute Care PhysTher. 2016;7:55-64.

9. Rosenfeldt AB, Covert S. Physical therapy intervention for an individual with severe thrombocytopenia. J Acute Care PhysTher. 2017;8:133-140.

10. Baumann FT, Zopf EM, Nykamp E, et al. Physical activity for patients undergoing an allogeneic hematopoietic stem cell transplantation: benefits of a moderate exercise intervention. European Journal of Haematology. 2011;87:148-156

11. Oechsle K, Aslan Z, Suesse Y, et al. Multimodal exercise training during myeloablative chemotherapy: a prospective randomized pilot trial. Support Care Cancer. 2014;22:63-69.

12. Jarden M, Hovgaard D, Boesen E, et al. Pilot study of a multimodal intervention: mixed-type exercise and psychoeducation in patients undergoing allogeneic stem cell transplantation. Bone Marrow Transplantation. 2007;40:793-800.

13. Wehrle A, Kneis S, Dickhuth $\mathrm{HH}$, et al. Endurance and resistance training in patients with acute leukemia undergoing induction chemotherapy - a randomized pilot study. Supportive Care in Cancer. 2018;27:1071-1079.

14. Wiskemann J, Kuehl R, Dreger P, et al. Efficacy of exercise training in SCT patients-who benefits most?. Bone Marrow Transplantation. 2014;49:443-448.

15. Elter T, Stipanov M, Heuser E, et al. Is physical exercise possible in patients with critical cytopenia undergoing intensive chemotherapy for acute leukaemia or aggressive lymphoma?. Int J Hematol. 2009;90:199204. 